\title{
Ensaio
}

\section{Diplomacia da saúde e cooperação Sul-Sul: as experiências da Unasul saúde e do Plano Estratégico de Cooperação em Saúde da Comunidade de Países de Língua Portuguesa (CPLP)}

\author{
DOI: 10.3395/reciis.v4i1.351pt
}

\section{Paulo Marchiori Buss}

Professor e pesquisador da Escola Nacional de Saúde Pública da Fundação Oswaldo Cruz, (ENSP-Fiocruz); Diretor do Centro de Relações Internacionais em Saúde (CRIS) Fiocruz; ex-Presidente da Fiocruz; Membro Titular da Academia Nacional de Medicina buss@fiocruz.br

\section{José Roberto Ferreira}

Doutor Honoris Causa da ENSP-Fiocruz; Chefe da Divisão de Cooperação Internacional do CRIS, Fiocruz; Ex-Diretor da Divisão de Recursos Humanos da Organização Panamericana de Saúde.

ferreirj@fiocruz.br

\begin{abstract}
Resumo
O artigo apresenta as principais características da cooperação internacional em saúde realizada recentemente em contextos regionais, que se inscrevem no âmbito da cooperação Sul-Sul. Tal cooperação se desenvolve particularmente entre países da América do Sul, no contexto da Unasul Saúde, e entre os Palop (Países Africanos de Língua Oficial Portuguesa), Timor Leste, Brasil e Portugal, no contexto do PECS/ CPLP (Plano Estratégico de Cooperação em Saúde da Comunidade de Países de Língua Portuguesa).
\end{abstract}

\section{Palavras-chave}

cooperação internacional em saúde; diplomacia da saúde; cooperação Sul-Sul;

Unasul saúde; plano estratégico de cooperação em saúde da comunidade de países de língua portuguesa
A cooperação Sul-Sul nas áreas sociais vem recebendo crescente atenção dos países em desenvolvimento do hemisfério sul, seja pelas limitações relativo da cooperação tradicional Norte-Sul, dominada pela visão e práticas centralizadoras dos países desenvolvidos, seja pela entrada de países emergentes de renda média no cenário da cooperação internacional, seja, ainda, pelos benefícios que países mais pobres vislumbram nesta 'cooperação entre semelhantes' (BUSS \& FERREIRA, 2010).

De outro lado, decorridos 30 anos da Conferência das Nações Unidas sobre Cooperação Técnica entre Paises em Desenvolvimento (CTPD) que, em 1978, com o Plano de Ação de Buenos Aires, lançou o conceito e a prática da cooperação Sul-Sul, também, as Nações Unidas, cedendo às demandas dos países do sul, revisita esta agenda, realizando em Nairobi, Quênia, em dezembro de 2009, a Conferência de Alto Nível das Nações Unidas sobre Cooperação Sul-Sul, tendo como tema principal a 'Promoção da Cooperação Sul-Sul para o
Desenvolvimento' (SOUTH-SOUTH CONFERENCE, 2009).

O presente artigo analisa duas iniciativas de cooperação Sul-Sul em saúde de existência muito recente: a Unasul Saúde, no âmbito do novo bloco regional que reúne os doze países da América do Sul; e o Plano Estratégico de Cooperação em Saúde da Comunidade de Países de Língua Portuguesa (PECS/CPLP), desenvolvido pelos oito países integrantes desta comunidade lingüística que se estende por quatro Continentes.

Pela prioridade conferida pelos mais altos dirigentes de ambos os blocos à cooperação em saúde, também creditamos tais experiências na chamada 'diplomacia da saúde' (Kickbusch et al., 2007), recém constituída como campo de prática nas relações internacionais.

\section{A cooperação Sul-Sul: marco conceitual ${ }^{1}$}

A cooperação Sul-Sul é o processo de interação econômica, comercial, social ou de outra natureza que se estabelece (idealmente) com vantagens mútuas entre parceiros de paises 
em desenvolvimento, geralmente localizados no hemisfério sul.

O conceito político Sul-Sul começa a se estabelecer na década de 1950, no auge da Guerra Fria, podendo-se demarcar a Conferência Ásia-África, realizada em Bandung, Indonésia, em 1955, como seu marco político inicial. Com o Movimento dos Não-Alinhados, estabelecido em 1961, na Conferência de Belgrado e, mais tarde, com a constituição do Grupo dos 77 (1964) - organização que na verdade hoje reúne cerca de 130 países - por ocasião da criação da $U N_{C T A D}{ }^{2}$, vão se construindo os marcos essenciais para a construção de consensos políticos entre países em desenvolvimento.

Em 1978, a Conferencia das Nações Unidas sobre Cooperação Técnica entre Países em Desenvolvimento (CTPD), celebrada em Buenos Aires, em 1978, demarcou mais uma etapa essencial, em que CTPD caracteriza-se como componente essencial da cooperação Sul-Sul. Segue-se, ainda neste ano, a criação da Unidade Especial para a Cooperação Sul-Sul (Special Unit for South-South Cooperation [SU/ SSC]), estabelecida pela Assembléia Geral das Nações Unidas também em 1978 e localizada no Programa das Nações Unidas para o Desenvolvimento (PNUD/UNDP), que passa a promover, coordenar e apoiar as cooperações Sul-Sul e triangular em bases globais e da própria ONU.

Em 1987 instala-se a Comissão do Sul (The South Commission), formada por 28 líderes de países do sul, entre os quais os brasileiros Dom Paulo Evaristo Arns e Celso Furtado, para expandir a cooperação Sul-Sul; seu Informe (The South Commision, 1990) torna-se um clássico e uma referência mundial sobre o tema.

Na década de 1990, mas com acentuada proeminência na primeira década deste século, observa-se o surgimento de paises emergentes de renda média e renda média alta como atores políticos de relevo no cenário internacional e, por conseqüência, na cooperação Sul-Sul. Com o intuito de realçar a capacidade de intervenção positiva na política internacional, tais economias emergentes desenvolvem, conjuntamente, fundos de investimento, programas de integração econômica, projetos de desenvolvimento, projetos de infra-estrutura e políticas de internacionalização de suas empresas.

Assim, países como Brasil, China, Índia, Nigéria, África do Sul e Venezuela e outros passam a fazer investimentos econômicos produtivos e cooperação em suas regiões ou em países africanos e asiáticos mais pobres, utilizando-se basicamente do chamado soft power diplomático (NYE, 2008), isto é, recursos de pessoal e tecnologias apropriadas na cooperação com países em menor grau de desenvolvimento, ao invés dos tradicionais mecanismos de coerção política ou manu militari para impor sua presença. Trata-se, na realidade, de um processo de cooperação entre países econômica e politicamente mais semelhantes do que entre muitos dos países desenvolvidos e ricos e os países pobres das referidas regiões. As áreas da agricultura, saúde, educação e construção de institucionalidade estão entre as principais áreas recentemente cobertas pela cooperação Sul-Sul.

O conceito da 'diplomacia da saúde' (Kickbusch et al., 2007; Buss, 2008) emergiu para tratar dos fatores da saúde que transcedem as fronteiras nacionais e expõe os países às influências globais. Esta noção também possibilita uma coordenação melhor e mais coesa entre os setores de saúde e relações exteriores dos governos, não apenas nutrindo a aceitação dos objetivos vinculados à saúde contidos nas Metas de Desenvolvimento do Milênio, como também assegurando a incorporação das mesmas nas plataformas de saúde e desenvolvimento das países. Diversos países vêm se destacando na cooperação em saúde como parte de iniciativas relevantes em política externa, a exemplo de Cuba. Este país tem sido um importante ator político na cooperação Sul-Sul, exportando tecnologias inovadoras na área da biotecnologia e de equipamentos em saúde, assim como disponibilizando recursos humanos (médicos e enfermeiros, principalmente) para sistemas de saúde reconhecidamente carentes de mão de obra qualificada.

Outro processo em alta, agora no âmbito da cooperação norte-Sul-Sul é a 'triangulação', modalidade de cooperação técnica na qual dois países implementam ações conjuntas com o objetivo de prover capacitação profissional, fortalecimento institucional e intercâmbio técnico para um terceiro. Os dados globais são ainda imprecisos, mas o exemplo do Brasil, que tem desenvolvido triangulações importantes com a Jica (agência japonesa para a cooperação) na África e, muito recentemente, ensaia cooperação triangular com o Departamento de Estado dos Estados Unidos com El Salvador e Moçambique, pode ser indicativo de um crescimento da cooperação triangular em saúde.

A crescente importância da cooperação Sul-Sul pode também ser aquilatada por três importantes eventos internacionais de alto nível realizados no transcorrer do último ano: a Reunião Plurianual de Especialistas sobre Cooperação Internacional, com foco na cooperação Sul-Sul e integração regional, realizada por ocasião da reunião da UNCTAD, em fevereiro de 2009, em Genebra (ICTSD, 2009); a Conferência de Alto Nível das Nações Unidas sobre Cooperação Sul-Sul (SOUTH-SOUTH CONFERENCE, 2009), realizada em Nairóbi, 
em dezembro de 2009; e, focando especificamente neste campo de políticas e práticas recém inaugurado da diplomacia da saúde, como menções destacadas para a cooperação SulSul, a reunião de alto nível do Conselho Econômico Social das Nações Unidas sobre Saúde Global, realizada em Genebra, em julho de 2009.

\section{A cooperação em saúde no âmbito da CPLP: - Plano Estratégico de Cooperação em Saúde (PECS/CPLP)}

A CPLP é composta de oito Estados membro: Brasil nas Américas; Portugal na Europa; Timor Leste na Ásia

\title{
Quadro 1 - Comunidade dos Países de Língua Portuguesa (CPLP)
}

\begin{abstract}
A comunidade dos países onde o português é a língua oficial foi criada em 1996 em Lisboa, Portugal, pelos chefes de Estado de Angola, Brasil, Cabo Verde, Guiné-Bissau, Moçambique, Portugal e São Tomé e Príncipe. Com sua independência em 2002, Timor Leste se tornou o oitavo membro da Comunidade. Ademais, a Guiné Equatorial, Ilhas Mauricius e Senegal são países observadores associados à CPLP.

Seus objetivos principais são a concertação político-diplomática entre os Estados membros visando reforçar suas presenças e da Comunidade no cenário internacional; a cooperação em todos os domínios, inclusive os da educação, saúde, ciência e tecnologia, defesa, agricultura, administração pública, comunicações, justiça, segurança pública, cultura, desporto e comunicação social; e a promoção e difusão da língua portuguesa.

A CPLP compõe-se de órgãos de direção e executivos: Conferência de Chefes de Estado e Governo; Conselho de Ministros das Relações Exteriores; Comitê de Concertação Permanente; Secretariado Executivo; Reuniões Ministeriais Setoriais (como a Reunião de Ministros da Saúde); e Reunião dos Pontos Focais de Cooperação; além do Instituto Internacional de Língua Portuguesa (IILP). A Assembleia Parlamentar é o órgão que reúne as representações de todos os Parlamentos da Comunidade, constituídas na base dos resultados eleitorais das eleições legislativas dos respectivos países.

As Conferências de Chefes de Estado e de Governo, órgão máximo de deliberação da CPLP, realizam-se a cada dois anos, já tendo sido realizadas sete, a última das quais em 2008, em Lisboa. O Conselho de Ministros reúne-se anualmente, representa os Presidentes e coordena as atividades da CPLP. O Comitê de Concertação é formado por um representante de alto nível de cada país e se reúne mensalmente, sendo responsável pelo acompanhamento sistemático da implementação das decisões dos demais órgãos da Comunidade.

As Reuniões Ministeriais Setoriais são constituídas pelos Ministros dos diferentes setores governamentais de todos os Estados-membros. Compete às Reuniões Ministeriais coordenar, ao nível ministerial ou equivalente, as ações de concertação e cooperação nos respectivos setores governamentais. A Reunião dos Pontos Focais de Cooperação congrega as unidades responsáveis, nos Estados-membros, pela coordenação da cooperação no âmbito da CPLP.

O Secretariado Executivo é o principal órgão executivo da CPLP, sediado em Lisboa, e dirigido por um Secretário com mandatos de dois anos, renováveis por mais dois. O atual Secretário Executivo é oriundo da Guiné Bissau e o cargo já foi ocupado, desde 1996, por altas personalidades de Angola, Brasil e Cabo Verde. O Secretário Executivo é auxiliado nas suas funções pelo Diretor Geral, recrutado entre os cidadãos nacionais dos Estados-membros, mediante concurso público, pelo prazo de 3 anos, renovável por igual período; o Diretor Geral é o responsável, sob a orientação do Secretário Executivo, pela gestão corrente da CPLP. A CPLP conta atualmente com 44 observadores consultivos, instituições científicas, culturais econômicas dos países participantes que contribuem para alcançar os objetivos da Comunidade. Embora tenham se reunido informalmente antes, a primeira reunião setorial formal de Ministros da Saúde da CPLP ocorreu em Praia, Cabo Verde, em abril de 2008, quando se decidiu estabelecer o Plano de Cooperação Estratégica em Saúde para o período 2010 a 2012. Na esfera internacional, a CPLP também assinou acordos com várias agências das Nações Unidas, como a UNAIDS e, mais recentemente, a OMS na área da saúde. Foi estabelecido um acordo específico para documentação de saúde em português, o e-português, com a OMS, instituição na qual o projeto está abrigado.
\end{abstract}

Fonte: www.cplp.org, acessado em 18/11/2009. 
e cinco países na África (Angola, Moçambique, GuinéBissau, Cabo Verde e São Tomé e Príncipe), que são os Palop (Quadro 1).

Os países da CPLP têm grandes assimetrias entre si em termos não somente de sua população, que variava entre 191,8 milhões no Brasil a 158 mil em São Tomé e Príncipe, como também da renda per capita, cuja variação ia de US\$ 18.950 em Portugal a apenas US\$200 na Guiné-Bissau e US\$320 em Moçambique. Em 2005, Angola, Guine Bissau e Timor Leste tinham ao redor de 50\% de sua populações vivendo abaixo da linha internacional de pobreza (USD 1,25/ dia), enquanto esta cifra alcançava 75\% em Moçambique (UNICEF, 2009).

Ademais, existem grandes variações nos indicadores de saúde e na expectativa de vida: em 2007, a mortalidade de menores de cinco anos era de 198 por mil, em Guiné Bissau, de 168 por mil em Moçambique, de 158 por mil em Angola e de apenas 5 por mil em Portugal; a expectativa de vida variava de cerca de 78 anos em Portugal e 72 no Brasil para menos de 45 anos em Angola, Guiné Bissau e Moçambique. As melhorias nos indicadores de saúde nos Palop e Timor Leste desde 1990, embora tenham ocorrido, ainda são pequenas quando comparadas com as de outros países em condições sócio-sanitárias equivalentes (UNICEF, 2009).

As condições nutricionais também são ruins, quando se consideram indicadores de desnutrição infantil, baixo peso ao nascer ou outros indicadores, bem como o acesso a serviços básicos de saúde, como imunizações, cobertura pré-natal ou parto assistido por profissionais de saúde. O acesso ao saneamento básico também é altamente deficiente nos Palop e Timor Leste, o que contribui para a manutenção das más condições de saúde (UNICEF, 2009).

Os sistemas de saúde dos Palop e Timor Leste são ainda extremamente frágeis, com cobertura deficiente, insuficiência no número de unidades de serviços, dificuldades na governança, pessoal insuficiente e mal pago e configuração tecnológica pouco adequada ao perfil epidemiológico. O gasto em saúde é minúsculo, sequer cobrindo necessidades básicas da atenção primária. O apoio técnico e financeiro internacional mostra-se vital para o funcionamento mínimo dos sistemas de saúde dos Palop e Timor Leste.

Estas difíceis condições sociais e econômicas vividas pelos Palop e Timor Leste, recém saídos de situações de conflitos internos graves ${ }^{3}$ que, em muitos casos, destruíram infraestruturas e dificultam a construção de institucionalidades e governança eficazes, inclusive na área da saúde, levou os países membros da CPLP a identificarem na saúde um campo propício à cooperação solidária e ao intercâmbio de experiências inovadoras.

A eleição da cooperação Sul-Sul, entre os países da CPLP, foi uma alternativa 'natural', facilitada pela questão idiomática (a imensa maioria dos profissionais de saúde dos Palop, por exemplo, falam exclusivamente português e idiomas nativos), de um lado, e pelas identidades políticas, ideológicas e culturais, por outro. Embora com recursos financeiros escassos, o diferencial na cooperação em saúde na CPLP tem sido a abundância de recursos humanos qualificados $\mathrm{e}$ a oferta de programas de pós-graduação em áreas críticas da saúde, como saúde pública, saúde da mulher e da criança e doenças transmissíveis, em países como o Brasil e Portugal.

O modelo operativo para a cooperação em saúde adotado pelos países da CPLP baseia-se no desenvolvimento compartilhado de um Plano Estratégico de Cooperação em Saúde (PECS/CPLP) (CPLP, 2009), que toma profundamente em conta a situação sócio-sanitária dos países, suas capacidades de resposta aos principais problemas encontrados e os recursos técnicos e financeiros existentes, que possam solidariamente ser colocados à disposição dos demais, num processo de cooperação comprometida com os princípios de apropriação, alinhamento e harmonização.

Após tratativas iniciais conduzidas pelo Secretariado Executivo da CPLP, o Conselho dos Ministros da Saúde reuniu-se em Praia, Cabo Verde, em abril de 2008 e decidiu sobre o desenvolvimento do Plano. Nesta oportunidade, os então chamados 'pontos focais da saúde', funcionários de alto nível dos Ministérios da Saúde, indicados e 'empoderados' pelos respectivos Ministros, foram apontados como as instâncias responsáveis tanto pela identificação da 'oferta' de cooperação em saúde que cada país poderia fazer aos demais, quanto pelas 'necessidades' de cooperação visando o efetivo desenvolvimento do sistema de saúde do respectivo país e da Comunidade como um todo. Esta etapa foi realizada entre abril e setembro de 2008, num processo intensamente participativo que contou com visitas técnicas aos países da Fiocruz e do IHMT, responsáveis também pela elaboração da primeira versão do PECS.

Após dois anos de negociações (2007-2009), desenvolvidas com reuniões intercaladas do Conselho de Ministros (Praia, abril de 2008, e Rio de Janeiro, setembro de 2008) e do Grupo Técnico de Saúde (Lisboa, junho de 2007; Lisboa, junho de 2008; e Recife, março de 2009) e fortemente apoiado nos conceitos de apropriação, alinhamento e harmonização, o plano de cooperação consagrou-se como um grande pacto celebrado pelos ministros da saúde dos oito países, registrado na Declaração do Estoril (CPLP, 2009), em 
maio de 2009. A partir de então, o PECS/CPLP vem sendo implementado pelos países, em conjunto com o Secretariado da CPLP.

Reconhecendo as ligações entre saúde e desenvolvimento e atentando que a saúde é um direito fundamental e obrigação do Estado, o propósito principal do Plano é fixado como "o aperfeiçoamento dos sistemas de saúde dos Estados membros da CPLP, de forma a garantir o acesso universal a serviços de saúde de qualidade". As principais estratégias utilizadas são a capacitação de recursos humanos e a implementação de projetos estruturantes que reforcem a capacidade institucional dos sistemas de saúde.

Entre os resultados a serem alcançados estão as reduções das mortalidades infantil e materna, o acesso universal aos cuidados integrais de saúde com ênfase na atenção primária e à saúde reprodutiva, além da prevenção e combate às grandes endemias, como sejam VIH/SIDA, tuberculose e malária, doenças negligenciadas e doenças emergentes como a influenza/gripe AH1N1, em todos os casos com uma perspectiva de igualdade de gênero (CPLP, 2009).

A Declaração do Estoril (CPLP, 2009) enfatiza a necessidade de atuar sobre os determinantes sociais de saúde para que se alcancem os Objetivos de Desenvolvimento do Milênio, para o que o Plano também se destina. O Plano será harmonizado com e complementar aos Planos Nacionais de Saúde dos países membros. Ademais, reconhece a importância de envolver, colaborar e associar competências com a sociedade civil dos Estados membros que desenvolve projetos no domínio da saúde e desenvolvimento, assim como fortalecer as relações entre a CPLP, a comunidade internacional e os parceiros de desenvolvimento que atuam na área da saúde, alargando, desta forma, a presença da CPLP e dos países lusófonos no plano internacional

A estrutura da CPLP relativa à cooperação em saúde compõe-se do Conselho de Ministros da Saúde dos Estados membros, do Grupo Técnico de Saúde da CPLP - pontos focais indicados pelos respectivos Ministros para a formulação, implementação, acompanhamento e avaliação do PECS - e pelo Secretariado Executivo da CPLP, com suporte técnico formal da Fundação Oswaldo Cruz (Brasil) e do Instituto de Higiene e Medicina Tropical (Portugal).

A cooperação inclui sete eixos temáticos para a definição tanto de projetos prioritários como de metas a serem atingidas (CPLP, 2009):

1) formação e desenvolvimento da força de trabalho em saúde;

2) informação e comunicação em saúde;
3) investigação em saúde;

4) desenvolvimento do complexo produtivo da saúde;

5) vigilância epidemiológica e monitorização da situação de saúde;

6) emergências e desastres naturais;

7) promoção e proteção à saúde.

O primeiro dos eixos diz respeito à formação e desenvolvimento da força de trabalho em saúde, elemento crítico em qualquer sistema, mas que adquire contornos dramáticos na África, pela insuficiência de pessoal, baixos salários, falta de escolas de formação e de educação contínua, além do brain draining, que acaba retirando de muitos países os poucos profissionais lá formados. Um dos aspectos críticos é o desconhecimento da situação real, pelo que ficou decidida a criação de Observatórios de Recursos Humanos em Saúde em cada país, além de uma rede destes Observatórios no âmbito da CPLP. A formação dos técnicos de nível médio (técnicos de enfermagem, de laboratórios, de radiologia e imagem, agentes comunitários de saúde etc.), imprescindíveis para os serviços de saúde na maior parte dos países da África, será incrementada pela implantação de Escolas Técnicas de Saúde em todos os países e da respectiva rede da CPLP. Em novembro de 2009, em reunião realizada na Escola Politécnica da Saúde da Fiocruz, no Rio de Janeiro, foi criada a Rede de Escolas Técnicas de Saúde da CPLP e aprovado seu primeiro Plano de Trabalho trienal (EPSJV, 2009). Por outro lado, prevê-se a formação de altos dirigentes para o sistema e os serviços de saúde através do reforço às Escolas Nacionais de Saúde Pública, que também se reunirão numa rede operativa, e médicos especialistas em áreas prioritárias por meio do Centro Formação Médica Especializada nos Países de Língua Portuguesa, a ser criado em Cabo Verde, cuja nova Universidade também será incentivada. Exemplos vivos e recentes de projetos de cooperação que já vêem implementando essa linha estratégica de trabalho são os Mestrados em Saúde Pública e em Ciências da Saúde que a Fiocruz vem desenvolvendo, respectivamente, em Angola e Moçambique, com o fim de preparar, nos próprios países, os quadros críticos de alto nível para o desenvolvimento de sistemas e serviços de qualidade (SAVINO et al., 2009).

Tais iniciativas de formação de recursos humanos, assim como a educação continuada de profissionais, necessitam de recursos financeiros, de bibliografia e documentação, muitos deles ainda inexistentes na dura realidade da África e Timor. Por esta razão, o PECS/CPLP definiu também como segundo eixo prioritário a informação e comunicação em saúde. A criação do Portal CPLP Saúde e de Redes de Bibliotecas Virtuais e de Bibliotecas de Saúde em cada país, além da 
criação de uma revista científica da área da saúde da CPLP, inclusive com versão eletrônica, são as iniciativas prioritárias para dar sustentação ao desenvolvimento de sistemas de saúde e de pessoal de qualidade que repousem sobre a base das evidências propiciadas pela informação científica de alta qualidade. Além disso, a OMS (2008) criou o e-português, uma plataforma para apoiar o desenvolvimento de recursos humanos para a saúde nos países de língua portuguesa, através do fortalecimento da cooperação na área da informação, documentação e capacitação em saúde.

Também joga um papel importante a investigação em saúde, única forma de se produzir conhecimentos e evidências 'autóctones'. O desenvolvimento de estudos e pesquisas por instituições técnico-científicas de países da CPLP, com prioridades para as áreas de vigilância em saúde, gestão de sistemas de saúde e pesquisa biomédica, são o terceiro eixo prioritário no planejamento do PECS. A Comunidade já dispõe de inúmeras Instituições de alta qualidade, como a Fundação Oswaldo Cruz e outros institutos públicos brasileiros de pesquisa e desenvolvimento, além da extraordinária rede de Universidades existentes no Brasil e Portugal, com instituições como o Instituto de Higiene e Medicina Tropical, o Instituto Nacional de Saúde Ricardo Jorge, o Instituto Gulbenkian de Ciências e as tradicionais e novas Universidades portuguesas. Angola e Moçambique já dispõem de Universidades de alto nível, enquanto Guiné Bissau, Cabo Verde, São Tomé e Príncipe e Timor Leste caminham para, com o apoio dos demais, estabelecerem universidades que vão se integrar ao esforço de produção científica e inovações adequadas às demandas da saúde e dos sistemas de saúde da CPLP.

É possível que, no médio prazo, esta rede de institutos de investigação venha a gerar inovações que poderão configurarse como um complexo produtivo da saúde (GADELHA, 2006) e comunitário, que vise reduzir a dependência externa de produtos e equipamentos, dinamizar a economia do setor saúde e ampliar o acesso da população a estes insumos críticos, assim como, especificamente, desenvolver uma indústria autóctone. Esse é o quarto eixo do PEC/CPLP e um exemplo de cooperação desta natureza é o apoio do Brasil à implantação de uma fábrica estatal de produção de medicamentos básicos e antiretrovirais (e respectiva transferência de tecnologias) desenvolvido entre a Fiocruz e o Ministério da Saúde de Moçambique. Também neste eixo está prevista a implantação de uma rede de Centros Técnicos de Instalação e Manutenção de Equipamentos (CTIME), assunto crítico para os sistemas de saúde da CPLP, pois inúmeros equipamentos médicos doados acabam virando sucata por absoluta falta de manutenção e reparos.
Função essencial de saúde pública, a vigilância em saúde - quinto eixo prioritário do PECS/CPLP - inclui a monitorização da situação de saúde, assim como dos Objetivos de Desenvolvimento do Milênio (ODM), e é considerada área de mútuo interesse de todos os países. Os ODM representam, indiscutivelmente, um passo a frente em contextos de pobreza e desigualdades como se verifica nos Palop e Timor, por representarem um 'pacto de ações intersetoriais' que certamente terão grande repercussão sobre a saúde - como, de resto, já se tem comprovado em diversas conjunturas e formações sociais - razão pela qual precisam ser monitorados e seu cumprimento incentivado. Contudo, em avaliação recente sobre os três grandes ODM relacionados com a saúde no continente africano, a OMS alerta que, se nada for feito, nem esses indicadores mínimos de saúde e qualidade de vida serão alcançados. Além disso, as vigilâncias epidemiológica, sanitária e ambiental necessitam tecnologias de gestão e aplicação de ferramentas e instrumentos adequados, mas também da criação de estruturas laboratoriais (os Laboratórios Nacionais de Referência em Saúde Pública) capazes de garantir o diagnóstico oportuno e confiável e o tratamento de doenças de maior prevalência e das situações de risco sanitário e ambiental. Uma abordagem contemporânea é transcender a idéia de 'laboratórios isolados e voltados para doenças específicas ou grupos de doenças', optando-se pela construção de 'Institutos Nacionais de Saúde Pública' abrangentes em sua missão e funções, como os que a Fiocruz, em cooperação com a International Association of National Public Health Institutes (IANPHI, 2010), apóia em Moçambique e Guiné Bissau.

Países com níveis elevados de carências têm grandes dificuldades em lidar com o imponderável e o inesperado na área da saúde. Por esta razão, o PECS/CPLP identificou as emergências e desastres como área prioritária para a cooperação e solidariedade entre os países da Comunidade. Epidemias, terremotos, inundações, secas, para citar apenas algumas das inúmeras atribulações que as mudanças climáticas e outras alterações têm trazido ao mundo, exigem a coordenação de ações e a velocidade de respostas conjuntas e solidárias a situações de emergência nos Estados membros, especialmente nos Palop e no Timor Leste. O PECS prevê, como seu sexto eixo de prioridade, a cooperação para o estabelecimento de núcleos nacionais de resposta rápida e coordenada e a elaboração de um plano comunitário de apoio mútuo para situações de emergências sanitárias (incluindo crises sanitárias pós-emergências naturais; escassez aguda de medicamentos; surtos epidêmicos; carência aguda de recursos humanos etc.). 
Finalmente, o sétimo eixo prioritário diz respeito à promoção e proteção da saúde, incluindo o apoio às imunizações nos países da CPLP e a implantação de projetos pilotos de 'comunidades saudáveis', além do desenvolvimento local de ações intersetoriais para o enfrentamento dos determinantes sociais da saúde. A promoção da saúde é um campo recente de preocupação das autoridades sanitárias, como também, e principalmente, da população. Diferente da prevenção de doenças, agravos e fatores de risco, ou do tratamento depois que se instala a doença, a promoção é o campo de enfrentamento dos determinantes sociais da saúde (OMS, 2008), que demanda ações coordenadas entre o setor saúde e outros campos de políticas públicas, como saneamento, meio ambiente, habitação, educação, geração de trabalho e emprego e distribuição mais eqüitativa da renda. O Brasil implantou uma Comissão Nacional sobre Determinantes Sociais da Saúde (CNDSS, 2008), seguindo as recomendações da OMS, e pode contribuir para definições e efetiva implementação de políticas e ações intersetoriais no contexto dos países da CPLP. Também neste eixo de cooperação estão contemplados os chamados recursos tradicionais e alternativos, tais como curandeiros, bruxos e outros 'profissionais' e parteiras tradicionais, muito importantes no contexto de certos países da África.

Para o desenvolvimento dos eixos temáticos de cooperação, os Ministros da Saúde determinaram que o Plano enfatize o apoio ao pleno desenvolvimento dos Ministérios da Saúde como autoridade sanitária nacional e o fortalecimento da atenção primária de saúde (OMS, 2008a) como principal diretriz política, além do reforço às denominadas 'institutições estruturantes dos sistemas de saúde'4: Institutos Nacionais de Saúde Pública, Escolas Nacionais de Saúde Pública, Escolas Técnicas de Saúde, outros Institutos Nacionais - como os referentes à saúde da mulher e da criança, por exemplo - e as escolas de graduação das profissões da saúde (medicina, enfermagem etc.). Todas elas estariam sob uma estratégia dominante, a de geração de redes dinâmicas para a cooperação.

Além disso, diversos problemas de saúde também são abordados coletivamente pelos países da CPLP através das redes temáticas de malária, tuberculose, HIV-aids e doença falciforme. Outras áreas poderão ser incluídas mais tarde, incluindo as áreas de diplomacia da saúde e saúde e migração, por exemplo.

O último passo realizado para a implantação do PECS foi a reunião de 'parceiros para o desenvolvimento do PECS/CPLP' (Lisboa, outubro de 2009), na qual Brasil e Portugal anunciaram doações iniciais de USD 250 mil cada e o Banco Mundial se comprometeu com a concessão de um 'grant' de USD 500 mil, que passam a compor o Fundo de Saúde da CPLP, especialmente criado pelos ministros e secretariado para financiar as ações do PECS. Num gesto emocionante e de expressiva confiança no processo, o pequeno Timor Leste fez uma doação que chamou 'simbólica' de USD 25 mil para ajudar na viabilização do PECS.

A excelente recepção dos países ao PECS/CPLP, expressada pelos Pontos Focais de Cooperação, está levando a CPLP a aplicar modelos similares a outras áreas de cooperação social como a educação e o meio ambiente, entre outras.

A perspectiva é que toda esta ação abrangente de fortalecimento dos sistemas de saúde dos PALOP e Timor Leste, por meio da estratégia da 'cooperação estruturante em saúde' (ALMEIDA et al., 2009; BUSS \& FERREIRA, 2010), no contexto da cooperação Sul-Sul, contribua para melhorar a alarmante situação de vida e saúde de milhões de africanos e timorenses que falam o idioma de Camões e estão ligados por laços históricos, culturais e de solidariedade.

\section{Cooperação Sul-Sul na América do Sul: Unasul saúde}

Organizada anteriormente em dois principais blocos regionais (Mercosul e Comunidade Andina), os doze países da América do Sul agrupam-se agora como União de Nações Sul-Americanas (Unasul) (Quadro 2), criada formalmente em maio de 2008, em Brasília, num momento de reafirmação democrática e de emergência de governos populares na maioria dos países da região. Consideram alguns analistas que este bloco político regional representa o primeiro genuíno contrabalanço ao poder político dos Estados Unidos no hemisfério.

A emergência, no alvorecer do século XXI, da Unasul não é um evento fortuito; ao contrário, é precedida de diversas iniciativas, que incluem: a constituição da Alalc (Associação Latino-americana de Livre Comércio) (1960), depois transformada em Aladi (Associação Latino-americana de Integração) (1980); a criação do Pacto Andino (1969), transformado em Comunidade Andina de Nações (CAN) (1996); o Tratado da Cooperação Amazônica (OTCA) (1978); o Grupo do Rio (década de 1980); a constituição do Mercosul, por meio do Tratado de Assunção (1991) e sua ampliação nas décadas seguintes, com as incorporações da Bolívia, Chile e Venezuela, esta em 2006; a constituição da Casa (Comunidade Sul-americana de Nações), reunindo 
Mercosul e CAN, por meio da Declaração de Cuzco (2004), que se transforma em União de Nações Sul-americanas (2007); e, finalmente, a assinatura do Tratado Constitutivo da UNASUL, em reunião dos Chefes de Estado, em Brasília, em maio de 2008.

Em absoluto o processo de integração na América do Sul tem sido destituído de conflitos internos aos países ou entre as nações participantes. No front interno da maioria dos países, a Unasul é um projeto de alguns governantes, sequer conhecido e, muito menos, apoiado pelas populações nacionais (RIVAROLA, 2009). De outro lado, para outros analistas, as enormes desproporções econômicas e as diferenças culturais, sociais e político-ideológicos, além de conflitos territoriais históricos, estariam na raiz das dificuldades existentes entre os países para a consecução do projeto de integração sul-americana. A política de integração envidada pelo Brasil, por exemplo, é vista freqüentemente como 'imperialista', isto é, o Brasil estaria disposto a promover uma política de expansão e de domínio territorial, cultural e econômico e de defender uma integração baseada

Quadro 2 - União das Nações Sul-Americanas (Usan / Unasul)

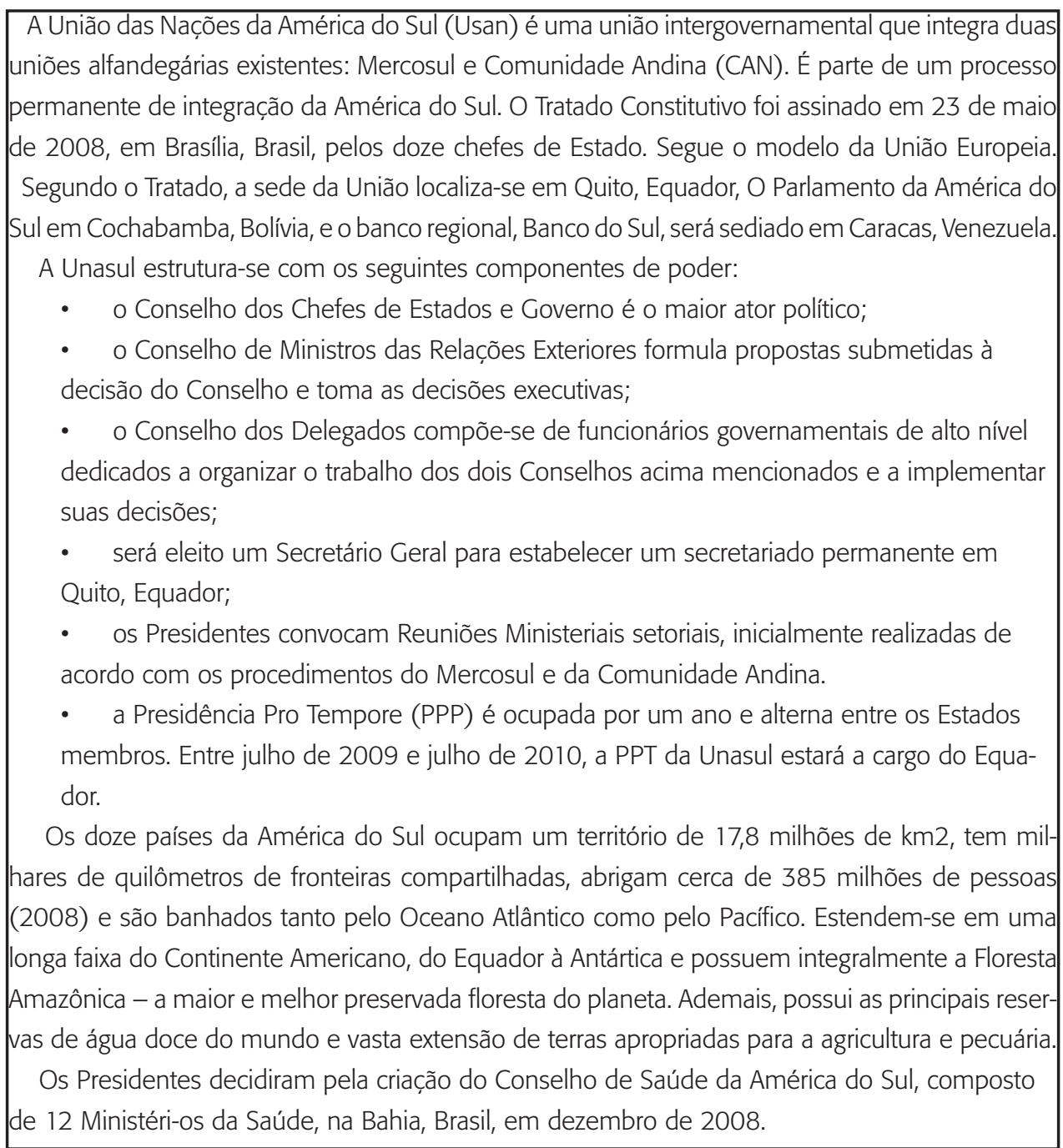

Fonte: www.unasur.org, acessado em 18/01/2010. 
principalmente nos interesses do empresariado brasileiro (BAVA, 2009; OUALALOU, 2010), representados pelo agronegócio (SILVA \& MELO, 2009), por projetos de infraestrutura (TAUTZ, 2009) e pela presença militar (GONZÁLES, 2009) e não numa agenda de realização de direitos (BAVA, 2009). A Alternativa Bolivariana para os Povos da Nossa América (Alba), da qual participam apenas três dos 12 países sul-americanos (Bolívia, Equador e Venezuela), propõe a criação de uma estrutura monetária regional, o Sucre (Sistema Unitário de Compensação Regional) que, segundo Cassen (2009), em resposta ao liberalismo quebraria o monopólio do FMI, não conta com o apoio dos demais, que discutem exclusivamente a ampliação do uso de moedas nacionais nos negócios internacionais dentro do bloco (CARVALHO, 2009). Já a implantação do Banco do Sul, importante estrutura da Unasul, cuja criação está decidida pelos dirigentes do bloco, avança lentamente devido às resistências levantadas pelo Brasil (CASSEN, 2009).

A despeito dos conflitos mencionados, a Unasul veio a se implantar politicamente, com a base de que num mundo cada vez mais globalizado e regionalizado, a constituição de organismos regionais amplos, comprometidos com o desenvolvimento de cada país e da região como um todo, com clamores de eqüidade, dá o tom dos entendimentos multilaterais vigentes neste início de século XXI.

Decorrência lógica da geografia e da história, a prioridade da América do Sul na política externa brasileira foi constante durante o Império e se mantém imutável também desde o início da República, embora com uma substantiva mudança nas relações políticas e econômicas entre o Brasil e as demais nações sul-americanas no transcorrer do século XX. As ênfases, os resultados e o sentido dessa política têm variado em função do momento histórico e da heterogeneidade do conjunto de países vizinhos (SANTOS, 2009).

Sintetizando a visão positiva da diplomacia brasileira quanto ao projeto de integração, Simões (2009) afirma que "a UNASUL inaugura uma fase sem precedentes nas relações internacionais da América do Sul (...), representando uma 'mudança de paradigma' no relacionamento sul-americano, oportunidade real de aceleração do desenvolvimento econômico e social dos países membros e possibilidade concreta de maior projeção da região num mundo multipolar".

A Unasul tem como objetivo "construir, de forma participativa e consensual, um espaço de integração e união nos campos cultural, social, econômico e político entre seus povos, outorgando prioridade ao diálogo político, às políticas sociais, saúde, educação, energia, infra- estrutura, financiamento e meio ambiente, entre outros, com vistas a eliminar as desigualdades sócio-econômicas, lograr a inclusão social e a participação cidadã, fortalecer a democracia e reduzir as assimetrias, no marco do fortalecimento da soberania e independência dos Estados membros" (UNASUL, 2008).

Sua primeira reunião de Chefes de Estado e de Governo no Brasil, realizada em Costa do Sauípe, Bahia, de 16 a 18 de dezembro de 2008 (UNASUL, 2008), culminou com diversas declarações políticas e a constituição do Conselho SulAmericano de Defesa e do Conselho Sul-Americano de Saúde demonstrando, com este último, a prioridade do tema e da agenda de saúde entre os líderes políticos da América do Sul.

O Conselho é composto pelos Ministros da Saúde dos doze Estados-membros. A Unasul Saúde tem como propósito consolidar a integração da América do Sul na saúde através de políticas baseadas em acordos mútuos, atividades coordenadas e esforços de cooperação entre os países (UNASUL SAÚDE, 2009).

A estrutura do Conselho inclui um Comitê de Coordenação, composto de representantes dos Ministérios de todos os países; uma Secretaria Técnica, composta pelo país que ocupa a Presidência Pro Tempore da Unasul, mais o país que a ocupou imediatamente antes, e o país que a ocupará imediatamente depois, com o intuito de dar continuidade ao processo, e Grupos Técnicos (GT) que se dedicarão a desenvolver a Agenda.

A Agenda Sul-Americana de Saúde aprovada pelo Conselho e a ser desenvolvida pelos GTs com representantes de todos os países, contempla uma amplitude temática que inclui os seguintes elementos substantivos (UNASUL Saúde, 2009):

1) elaborar a Política Sul-americana de Vigilância e Controle de Eventos em Saúde, antes 'escudo epidemiológico sul-americano';

2) desenvolver sistemas universais de saúde;

3) promover o acesso universal a medicamentos e outros insumos para a saúde e desenvolver o complexo produtivo da saúde na América do Sul;

4) promover a saúde e enfrentar de forma conjunta seus determinantes sociais;

5) desenvolver recursos humanos em saúde.

A Política Sul-americana de Vigilância e Controle de Eventos em Saúde visa estabelecer um registro regional de indicadores de morbi-mortalidade padronizados; promover o trabalho e atuação conjunta na vigilância e controle de enfermidades em áreas de fronteira; criar, fortalecer, consolidar e articular redes sul-americanas de vigilância e controle epidemiológico; 
e identificar as doenças que devem ser focadas de maneira prioritária. A cooperação entre os países buscará fortalecer os serviços públicos nacionais de vigilância epidemiológica, dotando-os de ferramentas e instrumentos técnico-científicos e gerenciais adequados e mobilizando os recursos nacionais e subcontinentais de diversas fontes e naturezas para tanto. Segundo o GT Vigilância (UNASUL Saúde, 2010), reunido em Assunção, Paraguai em julho de 2009 e em fevereiro de 2010, a política sul-americana de vigilância epidemiológica, elaborada e implementada considerando o Regulamento Sanitário Internacional, se debruçará sobre as situações dependentes de ações nacionais e regionais, como as doenças transmissíveis, as doenças crônicas nãotransmissíveis (neoplasias e problemas cardiovasculares, entre outras), as que acometem mulheres e crianças, as decorrentes de violência e outras causas externas etc. Outro componente importante nesta agenda é o fortalecimento de um Programa Sul-americano de Imunizações, de forma a alcançar cobertura universal da população com vacinas adequadamente indicadas pelo perfil epidemiológico vigente.

Para modificar a reconhecida insuficiência dos sistemas de saúde sul-americanos, o segundo componente da Agenda Sul-Americana de Saúde é a construção de 'sistemas universais e eqüitativos de saúde'. Sistemas universais de saúde são aqueles que, desenvolvendo diversos arranjos, propiciam às populações o acesso a todos a serviços de saúde pública e de atenção individual. Com esse tipo de direito assegurado, as ações assistenciais e de saúde pública de qualidade adquirem proeminência e são implementadas conforme as necessidades sócio-sanitárias. O complemento sub-regional se dá pelo desenvolvimento da 'saúde nas fronteiras' e pela garantia da 'portabilidade', quer dizer, o acesso aos serviços de saúde nacionais de sul-americanos não residentes no país em que procuram auxílio, segundo regulamentação a ser definida. O fortalecimento da harmonização das contas em saúde também se encontra entre as prioridades do GT, definidas em reunião realizada em Santiago, Chile, em outubro de 2009 (UNASUL Saúde 2009a).

Sistemas de saúde, porém, são estruturas tecnológicas complexas: dependem de equipamentos médico-cirúrgicos, medicamentos, vacinas, kits para diagnóstico, órteses e próteses, sangue e hemoderivados, materiais de consumo e outros insumos, além de instalações cada vez mais especializadas. Além de enfrentar desafios como o acesso a novos produtos e a regulação do mercado farmacêutico frente às novas biotecnologias, genômica e proteômica, o acesso a algo desse porte deve ser considerado no marco de políticas de saúde, industrial e de ciência e tecnologia.
Tais recursos são produzidos pelo que se denomina 'complexo produtivo da saúde' (GADELHA, 2006), ou seja, pelo conjunto de empresas produtoras e de consumidores institucionais (governos, prestadores de serviços de saúde, hospitais etc.) e individuais de bens e serviços de saúde, além das instituições que elaboram inovações (universidades e empresas). É a essa complexidade que pretende responder o terceiro componente da Agenda Sul-Americana de Saúde, desenvolvido pelo GT reunido em Buenos Aires, em fevereiro de 2010 (UNASUL Saúde, 2010). A região tem enorme déficit comercial na balança relativa a insumos e serviços de saúde. A proposta implica que os insumos em saúde necessários para a população sul-americana devam ser produzidos, dentro do possível, pelo complexo produtivo da saúde instalado no próprio subcontinente o que aponta para a necessidade de uma articulação público-privada em nível regional, que harmonize políticas industriais e de C\&T nesse complexo.

Estudiosos, políticos e ativistas sociais reconhecem hoje, consensualmente, que a saúde é um produto social, mais do que apenas o resultado de processos biológicos. A abordagem dos determinantes sociais da saúde como diretiva para a solução de inúmeros problemas em escala global foi levantada pela Organização Mundial da Saúde (WHO, 2008) e o Brasil seguiu pelo mesmo caminho, com o estabelecimento da Comissão Nacional sobre Determinantes Sociais da Saúde (CNDSS, 2008). No âmbito da Unasul Saúde, os ministros compreenderam que existe também uma dimensão subregional que compõe e, ao mesmo tempo, impacta, os determinantes sociais da saúde. O GT específico sobre o tema esteve reunido em Caracas, Venezuela, em fevereiro de 2010 (UNASUL Saúde, 2010b), quando propôs o desenvolvimento de um processo de identificação dos principais DSS na região, assim como o desenvolvimento de políticas públicas, a partir da análise da situação e de experiências bem sucedidas de ação inter-setorial para adequadamente enfrentá-los, nos planos nacional e regional.

Finalmente, considerando que o sistema de saúde é intensivo e extremamente dependente da qualidade de sua força de trabalho, o GT específico propôs diversas iniciativas na área de desenvolvimento de recursos humanos em saúde da Agenda, em reunião realizada em setembro de 2009, no Rio de Janeiro (UNASUL Saúde, 2009b). Entre suas recomendações, encontrava-se a criação do Instituto SulAmericano de Governo em Saúde (ISAGS), medida aprovada pelos Ministros em reunião realizada em Guaiaquil, em novembro de 2009 (UNASUL SAÚDE 2009c).

O ISAGS tem o propósito de contribuir com os países 
sul-americanos no preparo dos dirigentes dos seus sistemas de saúde, face ao reconhecimento de que todas as iniciativas na Agenda de Saúde dependem da qualidade de condução e liderança, coordenação e gestão, formulação de políticas de saúde e intersetoriais, capacitação avançada, produção de conhecimento e outros aspectos relacionados às funções essenciais da saúde pública (Fesp) (OPS, 2002), inclusive o novo campo conceitual e de prática da diplomacia da saúde. Outra missão importante da nova Instituição será a gestão do conhecimento já existente e a produção daquele que ainda se faz necessário para a consecução de seus propósitos, de forma compartilhada com os atores sociais e políticos relevantes nas esferas sociais e da saúde da região.

O ISAGS será uma instituição de natureza comunitária, pertencente, portanto, a todos os países signatários da Unasul, e de caráter público, sediado no Rio de Janeiro. Terá uma estrutura pequena e flexível e articulará seu programa de trabalho com instituições nacionais e centros de formação e pesquisa equivalentes de países da região, através da integração com redes das chamadas 'instituições estruturantes dos sistemas de saúde' (ver abaixo).

Na mesma reunião de Guaiaquil (UNASUL Saúde, 2009c), o Conselho de Ministros decidiu pela elaboração Plano Quinquenal de Saúde da UNASUL (2010-2015), a partir da consolidação das recomendações dos cinco GT correspondentes aos pontos da Agenda Sul-americana de Saúde, determinando ao Comitê Coordenador que o apresente na reunião do Conselho a ser realizada no mês de abril de 2010, em Quito, Equador. Além disso, estabeleceu formalmente diversas iniciativas (UNASUL SAÚDE, 2009c) de alta importância para o desenvolvimento dos sistemas de saúde da região previstas na Agenda, entre as quais as ações conjuntas dos países no controle da dengue e da Influenza A H1N1, o Programa de Bolsas UNASUL Saúde e a constituição das redes de instituições estruturantes dos sistemas de saúde.

O conceito de 'coooperação estruturante' (ALMEIDA et al., 2009) implica na instituição das redes sul-americanas de Institutos Nacionais de Saúde Pública, de Escolas Nacionais de Saúde Pública e de Escolas Técnicas de Saúde, além de redes de graduações nas principais profissões da saúde e de institutos de assistência à saúde, como nas áreas de saúde da mulher e da criança, câncer e outros e a rede de assessorias internacionais dos Ministérios da Saúde. Estas redes passam a integrar o acervo a Unasul Saúde, com grande potencial de contribuições à formação de recursos humanos, à pesquisa e desenvolvimento tecnológico e à prestação de serviços de referência na região.
Também na América do Sul, mas fora do âmbito da Unasul, duas outras iniciativas devem ser mencionadas: Unila, na educação e o Pacto Pan-Amazônico em Pesquisa em Saúde.

A Unila (Universidade Federal da Integração LatinoAmericana) é uma iniciativa do governo brasileiro para treinamento de estudantes do Brasil e outros países da América do Sul em diversos campos do conhecimento, inclusive saúde. Localiza-se em Foz do Iguaçu, cidade brasileira de tríplice fronteira, compartilhada por Brasil, Argentina e Paraguai. Esta nova instituição admitirá até dez mil estudantes, realizará investigações e pesquisas, além do treinamento de estudantes - primeiro do Mercosul e, posteriormente, de outros países da América do Sul (Unasul) - em áreas de interesse comum.

A Rede de Pesquisa em Saúde da Amazônia foi criada por instituições científicas dos países que compartilham a floresta Amazônica (Bolívia, Brasil, Colômbia, Equador, Guiana, Peru, Suriname e Venezuela), com o objetivo de executar em conjunto projetos relevantes para a situação específica e complexa desta região vital para o planeta. Como todos sabem, a Amazônia é a maior floresta tropical do mundo e é essencial para a redução do aquecimento global. A população da região é relativamente escassa, mas apresenta problemas de saúde diretamente conectados à situação social e ambiental do lugar. O Brasil participará através da Rede de Pesquisa de Saúde da Amazônia (brasileira) - encabeçada pela Fiocruz e composta de 21 institutos da região, entre os quais oito universidades federais e importantes instituições científicas brasileiras, como o Instituto Nacional de Pesquisas da Amazônia (Inpa) e o Museu Goeldi. Os principais projetos que estão em implementação no momento são as Redes de Pesquisa relacionadas à malária, febres hemorrágicas (entre as quais a dengue) e sistemas de saúde.

Esse grande arranjo inter-governamental chamado Unasul Saúde é um extraordinário exemplo de 'cooperação SulSul' (FERREIRA \& BUSS, 2010) e de 'diplomacia da saúde' (KICKBUSCH et al., 2007; BUSS, 2008) que os países da América do Sul e seus Ministérios das Relações Exteriores e da Saúde oferecem ao mundo, associando a orientação técnica em saúde com o apoio do setor de relações exteriores, para abordar situações que transcendem as fronteiras nacionais e expõem os paises a influências globais.

Com os enfoques políticos e conceituais em implementação, a Unasul Saúde pode melhor identificar as questões cuja abordagem regional constitui um valor agregado com respeito à ação desenvolvida exclusivamente no âmbito nacional, ou seja, quando a integração favorece a 
identificação e a solução dos problemas, pois nem todas as questões sócio-sanitárias se beneficiam ao serem abordadas regionalmente e cada processo de integração deve ser capaz de identificar suas próprias necessidades e os mecanismos e recursos adequados para atendê-las.

Contudo, mais do que com o desejo de governos nacionais, sem dúvida um primeiro passo fundamental já implementado, a UNASUL apenas se materializará como 'união' de 'nações' e não exclusivamente como 'tratado intergovernamental' se houver, como nos alerta Rivarola (2009), "el involucramiento activo de lo que da en llamarse sociedad civil - déficit hoy compartido por la CAN y Mercosur; será el que permitirá trasegar de una 'integración de mercados,' sin memoria compartida, a una 'Unión', basada en identidades, culturas y derechos 'transciudadanos».

\section{Notas}

1. Para uma discussão mais ampla sobre cooperação Sul-Sul em saúde ver o ensaio de Buss e Ferreira (2010).

2. Na reunião de sua criação, em 1964, a UNCTAD sustentava as estratégias de autonomia industrial dos países do sul, sob controle dos poderes públicos, como a política de substituição das importações provenientes dos países desenvolvidos por produções locais (RUIZ-DIAZ, 2005).

3. Em 2010, comemoram-se os 35 anos de independência de todos Palop, que ocorreram em 1975, imediatamente após a Revolução dos Cravos, em Portugal.

4. Instituições estruturantes dos sistemas de saúde são as que têm capacidade de operacionalizar sistemas e serviços de saúde de maneira efetiva, eficiente e sustentável, em especial através do seu poder oficial, capacidade de gestão e de prestação de serviços em saúde (Ministérios da Saúde, por exemplo) e da aptidão de treinamento de profissionais de saúde e geração de dados úteis para a tomada de decisão, através de P\&D e do treinamento dos recursos humanos essenciais para o campo da saúde (Institutos Nacionais de Saúde, Escolas de Saúde Pública, Escolas de Saúde Técnicas/Vocacionais, outros Institutos e escolas de graduação em saúde, por exemplo) (BUSS, 2008 - artigo ainda não publicado).

\section{Referências bibliográficas}

BAVA, S. C. Gigante pela própria natureza. Le Monde Diplomatique Brasil, v.19, n.3, fevereiro, 2009.

BUSS, P. M. A UNASUL Saúde. Le Monde Diplomatique Brasil v.26, n.30-31, setembro, 2009.
BUSS, P. M.; FERREIRA, J. R. Ensaio crítico sobre a cooperação internacional em saúde. RECIIS, v.4, n. 1, 2010.

CARVALHO, C. E. Passos importantes, muitas dificuldades. Le Monde Diplomatique Brasil, v. 19, n. 10-11, fevereiro, 2009.

CASSEN, B. Resposta ao liberalismo. Le Monde Diplomatique Brasil, v. 19, n.9, fevereiro, 2009.

CNDSS. As causas sociais das iniqüidades em saúde no Brasil. Relatório Final da Comissão Nacional sobre Determinantes Sociais em Saúde do Brasil. Rio de Janeiro: Editora Fiocruz, 215 pp. (2008). Disponível em: http://www. cndss.fiocruz.br/pdf/home/relatorio.pdf. Acessado em: 14 dez. 2009.

CPLP. Declaração do Estoril e PECS/CPLP. 2009. Disponível em: http://www.cplp.org/Saúde.aspx?ID=353. Accessado em: 18 nov. 2009.

CONFERENCE ON SOUTH-SOUTH COOPERATION. 2009. Disponível em: http://southsouthconference.org/?page_ id=6. Acessado em: 12 fev. 2010.

ECOSOC. 2009. Disoníve em: http://www.un.org/en/ecosoc/ julyhls/index.shtm. Acessado em: 12 fev. 2010.

EPSJV. Rede de Escolas Técnicas de Saúde da CPLP. (2009. Disponível em: http://www.epsjv.fiocruz.br/index.ph $\mathrm{p}$ ?Area $=$ Noticialnterna\&Destaque $=0 \&$ Num $=96$. Acessado em: 22 dez. 2009.

FIOCRUZ. 2010. Disponível em: http://www.fiocruz.br Acessado em: 19 dec., 2009

GADELHA, C. A. G. Desenvolvimento, complexo industrial da saúde e política industrial. Rev. Saúde Pub. v.40, n. especial, p.1-23, 2006.

GONZALES, G. T. Pressão pela força. Le Monde Diplomatique Brasil, v. 19, n.6-7, fevereiro, 2009.

ICTSD. 2009. Disponível em: http://ictsd.org/i/news/ pontesquinzenal/40746. Acessado em: 12 fev. 2010.

KICKBUSCH, I, SILBERSCHMIDT, G.; BUSS, P. M. Global health diplomacy: The need for new perspectives, strategic approaches and skills in global health. Bull WHO, v.85, n.3, p.230-2, 2007.

MRE. Coordenação Geral de Cooperação Técnica entre Países em Desenvolvimento (CGPD), 2008. Disponível em: http://www.abc.gov.br/abc/abc_ctpd.asp. Acessado em: 12 jul., 2009. 
NYE, J. Public diplomacy and soft power. The Annals of the American Academy of Political and Social Science, v. 616, n. 1, p. 94-109, 2008.

OMS. 2008. E-portugues. Disponível em: http://www.who. int/eportuguese/en. Acessado em: 18 jan. 2010.

OUALALOU, L. Brasília oublie le 'complexe du chien bâtard'. Le Monde Diplomatique, v.670, p.17, janeiro, 2010.

PAHO. Health Agenda for the Americas. Washington: PAHO, 34 pp. 2007.

RIVAROLA, M. Latinoamérica, identidad e integración. Integração da América do Sul. Textos Acadêmicos, volume II. Rio de Janeiro: MRE/Funag, 17pp.

RUIZ-DIAS, H. O futuro da ONU: com a palavra, os países do Sul. 2005. Disponível em: http://diplo.uol.com.br/200509,a 1156 . Acessado em: 12 fev. 2010.

SANTOS, E. América do Sul. In: IV Conferência Nacional de Política Externa e Política Internacional: textos acadêmicos. Rio de Janeiro: Fundação Alexandre Gusmão, 2009.

SAVINO, W.; JANI, I. V.; FUMANE, J.; BUSS, P. M.; LEAL, M. C. Local generation of high-quality human resources for health research. Bull WHO, v.86, n.2, p. 1-2, 2008.

SILVA, M. A. M.; MELO, B. M. Soja: a expansão dos negócios. Le Monde Diplomatique Brasil, v.19, p.4-5, fevereiro, 2009.

SIMÕES, A.J.F. UNASUL: A América do Sul e a construção de um mundo multipolar. In: IV Conferência Nacional de Política Externa e Política Internacional: textos acadêmicos. Rio de Janeiro: Fundação Alexandre. 2009.

TAUTZ, C. Da ALCA à IIRSA. Le Monde Diplomatique Brasil 19: 7-8, fevereiro 2009.

THE SOUTH COMMISSION. The Challenge to the South - The report of the South Commission. New York: Oxford University Press, 325 pp., 1990.
UNASUL. 2008. Disponível em: http://www.unasur.org. Acessado em: 12 jan. 2010.

UNASUL SAÚDE. 2009. Disponível em: http://www.unasursalud.org. Acessado em: 2 fev. 2010.

UNASUL SAÚDE. 2009a. Relatório do Grupo Técnico de Desenvolvimento de Recursos Humanos em Saúde, Rio de Janeiro, setembro de 2009. Disponível em: http://www. unasur-salud.org. Acessado em: 2 fev. 2010.

UNASUL SAÚDE. 2009b. Relatório do Grupo Técnico de Sistemas Universais de Saúde, Santiago de Chile, outubro de 2009. Disponível em: http://www.unasur-salud.org. Acessado em: 2 fev. 2010.

UNASUL SAÚDE. 2009c. Resoluções da Reunião Extraordinária do Conselho de Saúde Sul-americano, Guaiaquil, Equador, novembro de 2009. Disponível em: http://www.unasur-salud.org. Acessado em: 2 fev. 2010.

UNASUL SAÚDE. 2010. Relatório do Grupo Técnico de Vigilância Epidemiológica, Assunción, fevereiro de 2010. Disponível em: http://umw.unasur-salud.org. Acessado em: 2 fev. 2010.

UNASUL SAÚDE. 2010a. Relatório do Grupo Técnico de Acesso Universal a Medicamentos [e Insumos para a Saúde], Buenos Aires, janeiro de 2010. Disponível em: http://www.unasur-salud.org. Acessado em: 2 fev. 2010.

UNASUL SAÚDE. 2010b. Relatório do Grupo Técnico de Promoção da Saúde e Determinantes Sociais da Saúde, Caracas, janeiro de 2010. Disponível em: http://www.unasursalud.org Acessado em: 2 fev. 2010.

WHO WORLD HEALTHORGANIZATION/Commission on Social Determinants of Health. Closing the gap in a generation Final report of the CSDH, Geneva: WHO, 2008. Disponível em: http://www.who.int/social_determinants/thecommission/ finalreport/en/index.html. Acessado em: 26 set. 2009. 